\title{
Physical activity, black carbon exposure, and DNA methylation in the FOXP3 promoter
}

Stephanie Lovinsky-Desir ${ }^{* *}$ D, Kyung Hwa Jung², Jacqueline R. Jezioro², David Z. Torrone², Mariangels de Planell-Saguer ${ }^{3}$, Beizhan Yan ${ }^{4}$, Frederica P. Perera ${ }^{5}$, Andrew G. Rundle ${ }^{6}$, Matthew S. Perzanowski ${ }^{5}$, Steven N. Chillrud ${ }^{4}$ and Rachel L. Miller ${ }^{2,5,7}$

\begin{abstract}
Background: Physical activity is associated with improvement in lung function; however, pollution exposure during physical activity can lead to a transient reduction in lung function. This paradoxical relationship may be linked to altered T regulatory (Treg) cell activity, which increases with exercise and suppresses airway inflammation, but decreases in association with exposure to air pollution. To clarify these relationships, we investigated buccal cell DNA methylation of the forkhead box p3 (FOXP3) gene promoter, a proposed biomarker of Treg activity. We hypothesized that active urban children would have lower FOXP3 promoter methylation, associated with better lung function compared to non-active children. We also hypothesized that this relationship would be attenuated by high exposure to the air pollutant black carbon (BC).

Methods: We performed a cross-sectional study of 135 children ages 9-14 who live in New York City. Activity was measured across 6 days. BC exposure was assessed by personal monitors worn for two 24-h periods, followed by lung function assessment. Buccal swabs were collected for DNA methylation analysis of three regions (six CpG sites) in the FOXP3 promoter.

Results: In multivariable regression models, overall, there was no significant relationship between physical activity and FOXP3 promoter methylation ( $p>0.05)$. However, in stratified analyses, among children with higher BC exposure $\left(\geq 1200 \mathrm{ng} / \mathrm{m}^{3}\right)$, physical activity was associated with $2.37 \%$ lower methylation in promoter 2 (CpGs $-77,-65$, and -58$)\left(\beta_{\text {estimate }}=-2.37 \%, p<0.01\right)$ but not among those with lower $B C$ exposure $\left(\beta_{\text {estimate }}=0.54 \%, p>0.05\right)$. Differences across strata were statistically significant $\left(p_{\text {interaction }}=0.04\right)$. Among all children, after controlling for $B C$ concentration, promoter 2 methylation was associated with reduced $\mathrm{FEV}_{1} / \mathrm{FVC}\left(\beta_{\text {estimate }}=-0.40 \%, p<0.01\right)$ and reduced $\mathrm{FEF}_{25-75 \%}$ ( $\beta_{\text {estimate }}=-1.46 \%, p<0.01$ ).

Conclusions: Physical activity in urban children appeared associated with lower FOXP3 promoter methylation, a possible indicator of greater Treg function, under conditions of high BC exposure. Reduced FOXP3 promoter methylation was associated with higher lung function. These findings suggest that physical activity may induce immunologic benefits, particularly for urban children with greater risk of impaired lung function due to exposure to higher air pollution. FOXP3 promoter buccal cell methylation may function as a useful biomarker of that benefit.
\end{abstract}

Keywords: Exercise, Air pollution, Buccal cells, Treg, Lung function, Spirometry, Biomarker

\footnotetext{
* Correspondence: sl3230@cumc.columbia.edu

${ }^{1}$ Division of Pediatric Pulmonology, Department of Pediatrics, College of

Physicians and Surgeons, Columbia University, 3959 Broadway CHC-745, New

York, NY 10032, USA

Full list of author information is available at the end of the article
} 


\section{Background}

While regular physical activity is believed to reduce the frequency of asthma symptoms [1], exposure to air pollution is a known trigger of asthma [2, 3]. Some studies suggest that engaging in physical activity in polluted areas may reduce lung function $[4,5]$, increase airway inflammation [6], and increase the risk of developing asthma [7]. One possible explanation is that increased minute ventilation during exertion could lead to increased pollutant deposition in the lungs $[8,9]$. Yet, the complex relationship between the benefits of regular physical activity and the risk associated with pollution exposure is not well understood.

Physical activity and exercise may improve overall health and lung function, particularly in individuals with asthma, by suppressing pro-allergic immune responses via the $\mathrm{T}$ regulatory (Treg) cell pathway $[10,11]$. In support of this, Lowder et al. used an allergic asthma mouse model to demonstrate that moderate intensity activity over 4 weeks resulted in increased number and function of Tregs isolated from the lung and mediastinal lymph nodes [11]. Similarly, in a study of adults, increased Treg polarization of lymphocytes was observed with regular physical activity over a 12-week period while there was no change in a less active control group [12]. In contrast, reduced Treg cell number and function has been linked to environmental pollution exposure. For example, Nadeau and colleagues reported significant impairment in Treg function among children with asthma in the highly polluted region of Fresno, California, compared to children living in the less polluted Stamford, California region [13]. The same group also linked impaired Treg function to high exposure to the polycyclic aromatic hydrocarbon (PAH) class of air pollutants [14]. Furthermore, both animal $[15,16]$ and human studies [17] have demonstrated that Tregs suppress airway inflammation and airway hyper-responsiveness in allergic asthma. Thus, altered Treg cell activity appears to underlie how exposure to pollution impacts the relationship between physical activity and airway disease.

Activation of the forkhead box p3 (FOXP3) transcription factor controls the differentiation and function of Treg cells [18]; thus, FOXP3 expression is an established marker of committed Treg cell populations and function [19]. Several studies have demonstrated that FOXP3 is regulated through epigenetic mechanisms [20, 21]. For example, in vitro models have established that demethylation of the FOXP3 promoter is critical to the stable expression of FOXP3 and the suppressive function of Tregs [22]. Among ex vivo Treg cells, increased FOXP3 promoter methylation has been inversely correlated with FOXP3 expression [23]. In addition, increased FOXP3 methylation has been linked directly to higher pollutant exposures including diesel exhaust particles [24], polycyclic aromatic hydrocarbons
(PAHs) [13, 14], and secondhand smoke (SHS) [23]. Black carbon (BC), like PAHs, is a component of particulate matter (PM) and a major element of "soot" which is an incomplete combustion product emitted from diesel exhaust. Similar to SHS, BC exposure has been associated with respiratory symptoms [25], airway inflammation [26], and reduced lung function [27]. Thus, BC exposure also may contribute to the pollution-associated increase in FOXP3 methylation and Treg impairment.

Our primary objective was to determine the interaction between physical activity and $\mathrm{BC}$ exposure on FOXP3 promoter methylation in a cross-sectional sample of 9-14-year-old children that live in New York City (NYC). An additional objective was to determine the relationship between FOXP3 promoter methylation and measures of lung function. We assessed FOXP3 methylation in buccal cells as a surrogate for airway epithelium. FOXP3 expression in buccal epithelium has been demonstrated by others [28], and FOXP3 methylation in saliva has been linked previously to both exposure to pollution and asthma outcomes [24]. While physical activity may induce improved immune function through increased Treg activity, increased lung deposition of pollutants during physical activity could mitigate this protective effect. Therefore, we hypothesized that overall, physical activity would be associated with lower FOXP3 promoter methylation, but that this association would lessen among those with high $\mathrm{BC}$ exposure. We also hypothesized that lower FOXP3 promoter methylation would be associated with higher lung function.

\section{Methods}

\section{Study population}

Study participants $(n=163)$ were enrolled from the Columbia Center for Children's Environmental Health (CCCEH) birth cohort that is comprised of children living in Northern Manhattan and the South Bronx of NYC, whose non-smoking, African American and Dominican mothers were recruited during pregnancy [29, 30]. Participants were recruited for this nested study based on age (target 9-14-year-olds) and current asthma. Asthma diagnosis was determined by a physician (allergist or pulmonologist) using standardized criteria during at least one cohort study visit between ages 5 and 12 years [31]. In addition, in order to be eligible for the nested study, children with asthma had to have report of asthma symptoms or asthma medication use in the 12 months prior to enrollment in the nested study. Total serum immunoglobulin $\mathrm{E}(\mathrm{IgE})$ was measured at age 9 or 11 . Children with a total IgE level $\geq 80 \mathrm{IU} / \mathrm{mL}$ were considered seroatopic. Children with body mass index (BMI) percentiles $\geq$ the 85th percentile for age and sex were classified as "overweight." Secondhand smoke exposure (SHS) was determined by answering yes to the question, "In the last 2 
weeks have you been exposed to tobacco smoke in the home." Complete data on physical activity, BC exposure, DNA methylation, and lung function were available for $n$ $=135$ children that were included in this study. The longitudinal birth cohort study is conducted in accordance with the Columbia University Institutional Review Board guidelines, and written informed consents and assents were obtained.

\section{Physical activity assessment}

All study participants wore an accelerometer (Actical, Philips Respironics, Bend, OR) continuously on the nondominant wrist for six consecutive days (Additional file 1: Figure S1). To account for 24-h data that were partially collected on the first and last day, only the five intervening consecutive days with full 24-h of data were used for analysis [6, 32]. The accelerometer uses a sensor to detect and integrate amplitude and frequency of motion and stores the data as activity counts. Based on the activity counts, activity energy expenditure is determined with a cut point of $<0.031 \mathrm{kcal} / \mathrm{min} / \mathrm{kg}$ for light activity, $>0.083 \mathrm{kcal} / \mathrm{min} / \mathrm{kg}$ for vigorous activity, and moderate intensity activity in between. Summary statistics derived from the Actical software were used to quantify the amount of time spent in moderate and vigorous activity for each 24-h period. Physical activity was characterized based on the Center for Disease Control and Prevention (CDC) recommendation that children should participate in at least $60 \mathrm{~min}$ of moderate-to-vigorous activity (MVA) on a daily basis (http://www.cdc.gov/physicalactivity/ everyone/guidelines/children.html). Children that met the physical activity recommendation, having at least $60 \mathrm{~min}$ of MVA daily, were considered "active" while children that did not meet the physical activity recommendation were considered "non-active" as previously published [6].

\section{Personal BC monitoring}

Personal exposure to $\mathrm{BC}$ was measured over two 24-h periods at the beginning and end of the week-long physical activity monitoring period (Additional file 1: Figure S1). Children carried a MicroAeth (Model AE51, Magee Scientific, Berkley, CA) inside a vest pocket that contained an air inlet in the breathing zone (vest collar). Children were instructed to remove the vest during vigorous activity and to keep it nearby and uncovered. We previously have demonstrated excellent compliance with wearing the $\mathrm{BC}$ monitoring equipment [33]. $\mathrm{BC}$ was sampled from the air every $5 \mathrm{~min}$ and data were cleaned according to algorithms developed to account for false positive and negative measures that can result from physical vibration $[34,35]$. Every $5 \mathrm{~min}$, data were then averaged to yield a mean 24$\mathrm{h}$ exposure assessment. Mean 24-h personal exposure to $\mathrm{BC}$ weakly correlated across the 2 days of measurement (Spearman $r=0.35, p<0.01$ ), reflecting some day to day variation in exposure. Therefore, personal $\mathrm{BC}$ exposure levels were averaged across the two 24-h monitoring periods and dichotomized at the median $\left(1210 \mathrm{ng} / \mathrm{m}^{3}\right)$ to represent high vs. low average exposure across the week. Fifty-three percent of the personal $\mathrm{BC}$ exposure measurements $(n=71)$ were sampled during the NYC cold weather heating season (i.e., from October to April).

\section{FOXP3 DNA methylation analysis}

Buccal samples were collected using the CytoSoft $\mathrm{Cy}$ tology brush [36, 37] (Fisher Scientific, Pittsburgh, PA, USA) from each child at two time points, 5 days apart corresponding to the 2 days of $\mathrm{BC}$ exposure assessment (Additional file 1: Figure S1). Samples contained approximately $94 \%$ squamous epithelial cells, determined by slide smear hematoxylin and eosin stain, as previously published [38]. Bisulfite conversion was performed on 200 ng of genomic buccal cell DNA using Zymo Research's EZ DNA Methylation-Lightning Kit (Irvine, CA, USA) as previously published $[37,38]$.

Polymerase chain reaction (PCR) primers and pyrosequencing primers (Additional file 2: Table S1) were designed using PyroMark Assay Design 2.0 software (Qiagen, Valencia, CA, USA) to target six CpG sites in the promoter region of the FOXP3 gene. The promoter region was defined as the gene region directly upstream of the transcription start site (TSS) (Additional file 1: Figure S2). The individual CpG sites were selected based on previous literature that demonstrated methylation in this region was associated with ambient air pollution exposure [13]. We chose to focus on CpG sites in the gene promoter which is the principal activator of FOXP3 expression [22] as opposed to CpG sites in the Treg-cellspecific demethylated region (TSDR) which play a role in stabilizing FOXP3 expression [39] and are only activated in Treg cells [40]. PCR reactions were performed with Qiagen Hot Star Taq DNA polymerase reagents (Qiagen Sciences, Germantown, MD, USA) with the following concentrations for each ingredient in the $\mathrm{PCR}$ mixtures: $1 \times$ PCR buffer, $1.5 \mu \mathrm{M} \mathrm{MgCl}_{2}, 200 \mu \mathrm{M}$ dNTP, $0.2 \mu \mathrm{M}$ forward primer, and $0.2 \mu \mathrm{M}$ reverse primer. PCR was performed under the following conditions: $95{ }^{\circ} \mathrm{C}$, $5 \mathrm{~min}$; 45 cycles of $95{ }^{\circ} \mathrm{C}, 30 \mathrm{~s} ; 57{ }^{\circ} \mathrm{C}, 1 \mathrm{~min} ; 72{ }^{\circ} \mathrm{C}$, $1 \mathrm{~min} ; 72{ }^{\circ} \mathrm{C}, 10 \mathrm{~min}$; and $4{ }^{\circ} \mathrm{C}$ hold. The PCR product was sequenced using PyroMark Q96 Pyrosequencer. EpiTect high and low methylated control DNA (Qiagen Sciences, Germantown, MD, USA) were included with every pyrosequencing experiment.

Three distinct promoter regions were defined by the proximity to neighboring $\mathrm{CpG}$ sites: promoter 1 included CpGs -138 and -126 ; promoter 2 included CpGs $-77,-65$, and -58 ; and promoter 3 included CpG -15 (Additional file 1: Figure S2). Percent methylation was moderately correlated across each promoter region $(r=$ 
$0.22-0.45, p<0.01)$. Therefore, percent methylation was averaged across the two CpG sites in promoter 1 and the three $\mathrm{CpG}$ sites in promoter 2. Percent methylation measured across the two separate days was moderately correlated for each of the promoter regions $(r=0.47-0.68$, $p<0.01$ ) (Additional file 2: Table S2). Therefore, in order to account for short-term variability in methylation across the 1 week of physical activity monitoring [36], methylation was averaged across the 2 days. For subjects in which there was only 1 day of methylation data available because of a laboratory technical failure $(n=8$ for promoter 1 and $n=2$ for promoter 2 ), the one available methylation value was used in place of an average.

\section{FOXP3 mRNA expression analysis}

A separate buccal swab was collected from each child and stored in RNAlater solution (Qiagen Sciences, Germantown, Maryland, United States). RNA was extracted using the Trizol method (Invitrogen, Life Technologies Europe BV, Monza, Italy) as previously published [37]. RNA concentration and purity was measured using a NanoDrop spectrophotometer (Thermo Scientific, Wilmington, DE, USA). Complementary (cDNA) synthesis of up to $200 \mu \mathrm{g}$ of RNA was transcribed with a SuperScript First-Strand Synthesis System for RT-PCR (Invitrogen, Life Technologies Europe BV, Monza, Italy) according to the manufacturer's instructions. Quantitative real-time PCR was performed using a $25-\mu \mathrm{l}$ reaction volume containing $2 \mu \mathrm{l} \mathrm{cDNA}$ template, $12.5 \mu \mathrm{l}$ SYBR Green Mix (Applied Biosystems, Foster City, CA, USA), $9.5 \mu \mathrm{l} \mathrm{H} 20$, and $0.2 \mu \mathrm{M}$ of forward and reverse primer (Additional file 2: Table S1). Amplifications were performed in duplicate with an initial incubation at $95{ }^{\circ} \mathrm{C}$ for $30 \mathrm{~s}$, followed by 40 cycles of $95{ }^{\circ} \mathrm{C}$ for $10 \mathrm{~s}$ and $55^{\circ} \mathrm{C}$ for $30 \mathrm{~s}$, using a CFX Connect Real-Time PCR Detection System (Bio-Rad, Hercules, CA, USA).

FOXP3 mRNA expression levels were determined using the $2^{-\Delta \mathrm{Ct}}$ method with cystatin A (CSTA) as a reference gene (highly and stably expressed in nonmalignant epithelial tissue [41]) and normalized to the lowest measured value. Across the 2 days of sampling, relative mRNA expression was moderately correlated $(r=0.31, p<0.01$, Additional file 2: Table S2); therefore, values were averaged across the 2 days. For the subjects for which there was insufficient template RNA and cDNA to perform real-time PCR experiments for one of the measurement days $(n=6)$, we used a single value in place of a 2-day average yielding a total sample size of 132 for all RNA analysis.

\section{Pulmonary function assessment}

Spirometry was used to assess pulmonary function during in-home visits on days 1 and 6 , immediately following BC assessment (Additional file 1: Figure S1). Studies were performed using a portable spirometer (Koko, nSpire Health,
Longmont, CO, USA), in accordance with ATS and ERS guidelines [31]. Four spirometry outcome measures were used for this analysis, forced vital capacity (FVC), forced expiratory volume in $1 \mathrm{~s}\left(\mathrm{FEV}_{1}\right)$, the ratio of $\mathrm{FEV}_{1} / \mathrm{FVC}$, and the forced expiratory flow at $25-75 \%\left(\mathrm{FEF}_{25-75 \%}\right)$. Spirometry results were interpreted independently by two pulmonologists to ensure acceptability criteria were met based on ATS and ERS guidelines [42].

\section{Statistical analysis}

Chi-square and $t$ tests were used to explore differences in demographic characteristics between the active and nonactive children. Spearman correlations were used to assess methylation correlations across promoter regions. KruskalWallis tests were used to determine the difference in FOXP3 promoter methylation between active vs. non-active children and between high vs. low $\mathrm{BC}$ concentrations.

Step-wise multivariable linear regression models were fit to examine the association between physical activity and FOXP3 promoter methylation with active (coded 1) vs. non-active (coded 0 ) as the main predictor of interest. Models were further stratified by high vs. low BC concentrations (dichotomized at the median). To assess for interaction, we introduced a cross product term of activity $\mathrm{x} B C$ concentration to our non-stratified models. Because FOXP3 promoter methylation was not normally distributed, we also performed a sensitivity analysis using ordinal logistic regression where methylation was categorized by quartiles. To examine the association of FOXP3 promoter methylation on lung function, we again performed step-wise linear regression models with percent methylation as the predictors of interest and $\mathrm{FVC}, \mathrm{FEV}_{1}, \mathrm{FEV}_{1} / \mathrm{FVC}$, and $\mathrm{FEF}_{25-75 \%}$ percent predicted as the outcomes.

To explore potential associations between activity, pollution, and FOXP3 expression, in the secondary analysis, we substituted relative mRNA expression for methylation in our above mentioned models. We also performed a secondary analysis to examine the relationship between physical activity and lung function. As an exploratory analysis, we further stratified our activity-lung function model by the upper tertile of $\mathrm{BC}$ concentration $\left(\geq 1790 \mathrm{ng} / \mathrm{m}^{3}\right)$ to isolate the children with the most extreme BC exposure concentrations. For these exploratory analyses, we chose to stratify by the upper tertile of $\mathrm{BC}$ based on our previous findings that physical activity was associated with decrease airway inflammation but not among children with the highest exposure to $\mathrm{BC}$ (upper tertile) [6]. Lastly, given that the FOXP3 gene is located on the X-chromosome and may be susceptible to X-chromosome inactivation (XCI) resulting in sex differences in methylation patterns [43, 44], we performed ancillary analyses stratified by sex. All final models were adjusted for the following covariates: age, sex (except in 
models stratified by sex), race/ethnicity, height (lung function models only), body mass index (BMI) Z-score [45], asthma, atopy (total $\mathrm{IgE} \geq 80 \mathrm{IU} / \mathrm{mL}$ ), personal $\mathrm{BC}$ concentration (except in the models stratified by $\mathrm{BC}$ ), SHS exposure, and heating season.

All statistical analyses were performed using SAS 9.4.

\section{Results}

\section{Subject characteristics}

Demographic characteristics for the 135 children included in this analysis are provided in Table 1. The children in the active group were slightly younger than the children in the non-active group $(p<0.01)$. There were fewer children in the non-active group with SHS exposure compared to children in the active group ( $p=$ $0.04)$. Average time spent $( \pm S D)$ in MVA across the 5day observation period among active children was $210 \mathrm{~min} /$ day $( \pm 84)$ and among non-active children was $101 \mathrm{~min} /$ day $( \pm 58)$.

Table 1 Participant characteristics for the $n=135$ children included in this study

\begin{tabular}{|c|c|c|c|}
\hline & $\begin{array}{l}\text { Non-active } \\
(n=58)\end{array}$ & $\begin{array}{l}\text { Active } \\
(n=77)\end{array}$ & $p$ value $^{\mathrm{a}}$ \\
\hline Age in years, median (range) & $12.7(10.5-14.0)$ & $12.2(9.2-14.0)$ & $<0.01$ \\
\hline Males, $n(\%)$ & $32(55 \%)$ & $35(45 \%)$ & 0.26 \\
\hline $\begin{array}{l}\text { Race/ethnicity, n (\%) } \\
\text { Hispanic } \\
\text { African American }\end{array}$ & $\begin{array}{l}42(72 \%) \\
16(28 \%)\end{array}$ & $\begin{array}{l}46(60 \%) \\
31(40 \%)\end{array}$ & 0.13 \\
\hline Asthma $^{\mathrm{b}}, n(\%)$ & $30(52 \%)$ & $45(58 \%)$ & 0.44 \\
\hline FVC \% predicted, mean (SD) & $85 \%(12.1)$ & $86 \%(10.5)$ & 0.92 \\
\hline $\mathrm{FEV}_{1} \%$ predicted, mean (SD) & $84 \%(13.0)$ & $85 \%(11.6)$ & 0.72 \\
\hline $\begin{array}{l}\mathrm{FEV}_{1} / \mathrm{FVC} \% \text { predicted, mean } \\
\text { (SD) }\end{array}$ & $87 \%(7.5)$ & $87 \%(5.3)$ & 0.52 \\
\hline $\begin{array}{l}\mathrm{FEF}_{25-75 \%} \% \text { predicted, mean } \\
\text { (SD) }\end{array}$ & $83 \%(24.2)$ & $86 \%(21.7)$ & 0.36 \\
\hline Total lgE $\geq 80 \mathrm{IU} / \mathrm{mL}$ & $31(53 \%)$ & $38(49 \%)$ & 0.64 \\
\hline BMI $\geq 85$ th percentile, $n(\%)$ & $31(53 \%)$ & $39(51 \%)$ & 0.75 \\
\hline Secondhand smoke ${ }^{c}, n(\%)$ & $3(5 \%)$ & $14(18 \%)$ & 0.04 \\
\hline Heating season ${ }^{d}, n(\%)$ & $25(43 \%)$ & $44(57 \%)$ & 0.11 \\
\hline Black carbon, GM (SD) & $1070(1.69)$ & $1190(1.78)$ & 0.25 \\
\hline High BC,$n(\%)$ & $26(45 \%)$ & 37 (48\%) & 0.71 \\
\hline
\end{tabular}

$F V C$ forced vital capacity, $F V E_{1}$ forced expiratory volume in $1 \mathrm{~s}, F E F_{25-75 \%}$ forced expiratory flow at $25-75 \%$, IgE Immunoglobulin $E, B M I$ body mass index, $B C$ black carbon

${ }^{a}$ Chi-square test for categorical variables and $t$ test for continuous variables (age and black carbon)

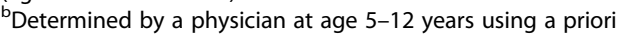
standardized criteria

'Determined by responding yes to the question "In the last 2 weeks have you been exposed to tobacco smoke in the home." missing $n=1$ from the active group

'Observation period took place during NYC's cold weather heating season (October to April)

eDichotomized at the median, $1210 \mathrm{ng} / \mathrm{m}^{3}$

Italicised values in the final column represent a $p$-value $<0.05$
Independent associations of physical activity and BC exposure on FOXP3 methylation

Buccal cell methylation in the FOXP3 promoter regions ranged from 62.9 to $95.1 \%$ (promoter 1: mean \pm SD, $80.0 \pm$ 4.8; promoter 2: $87.4 \pm 4.0$; promoter 3: $80.2 \pm 5.9$ ). We observed moderate correlations in FOXP3 methylation across the three promoter regions $\left(r_{\text {spearman }} 0.56-0.58, p<0.01\right)$ (Additional file 1: Figure S3). In bivariate analysis, active children had lower promoter 3 methylation $(79.2 \pm 6.1)$ compared to non-active children $(81.4 \pm 5.4, p=0.04)$ (Fig. 1). Also, children with high personal BC exposure had higher promoter 1 methylation compared to children with low BC $(80.9 \pm 4.8$ vs. $79.1 \pm 4.7, p=0.04)$ (Fig. 1$)$.

In multivariable linear regression models, we did not observe an association between physical activity and FOXP3 promoter methylation $(p=0.31,0.33$, and 0.35 for promoters 1,2 , and 3 , respectively) (Table 2 ).

\section{Combined association of physical activity and BC exposure on FOXP3 methylation}

We first compared FOXP3 promoter methylation across four groups of children (non-active/low $\mathrm{BC}$, active/low $\mathrm{BC}$, non-active/high $\mathrm{BC}$, and active/high $\mathrm{BC}$ ) (Fig. 2). Non-active children with high exposure to $\mathrm{BC}$ had the highest methylation in all FOXP3 promoter sites $(p<$ 0.05 , Fig. 2). We next performed multivariable linear regression models to examine the association between physical activity and FOXP3 methylation stratified by high vs. low $\mathrm{BC}$ concentrations. Among children with high personal $\mathrm{BC}$ measures $(n=63)$, active children on average had $2.4 \%$ lower promoter 2 methylation $\left(\beta_{\text {estimate }}\right.$ [95\% CI] $-2.37[-4.04,-0.70], p<0.01)$ and $2.6 \%$ lower promoter 3 methylation $(-2.57[-4.62,-0.51], p=0.01)$ compared to non-active children (Table 2). There was no significant association between physical activity and FOXP3 methylation among children with low personal BC concentration $(p>0.05)$ (Table 2$)$. We observed a significant interaction in the association between activity and promoter 2 methylation by $\mathrm{BC}$ concentration $\left(p_{\text {inter- }}\right.$ action $=0.04)$, but not with promoter 3 methylation $\left(p_{\text {inter- }}\right.$ action $=0.26)($ Table 2).

In sensitivity analysis using ordinal logistic regression, we again observed a trend towards an inverse association between activity and methylation among children with high $\mathrm{BC}(p=0.09,0.06$, and 0.07 for promoters 1,2 , and 3 , respectively) (Additional file 2: Table S3). There was no association between activity and methylation among children with low BC $(p>0.05)$.

\section{Association between FOXP3 methylation and lung function}

We next examined the association between FOXP3 promoter methylation and lung function outcomes. There was an inverse association between FOXP3 promoter 2 

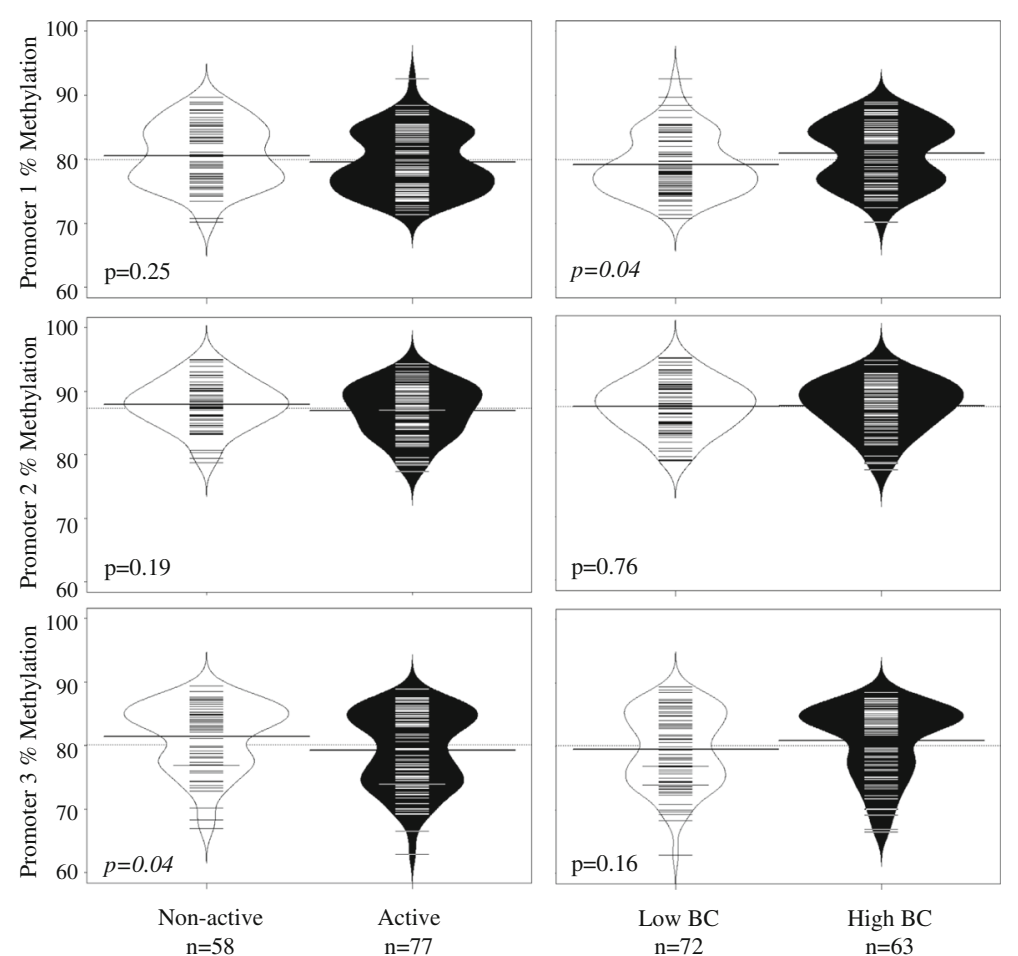

Fig. 1 Distribution of FOXP3 promoter methylation stratified by active vs. non-active children and by low vs. high black carbon (Kruskal-Wallis test). The short lines indicate individual observations, while the shaded areas indicated the distribution of the data for each respective group. The dotted lines indicate the mean percent methylation for all participants, and the thicker solid lines represent mean percent methylation for each respective group

methylation and both the $\mathrm{FEV}_{1} / \mathrm{FVC}$ and $\mathrm{FEF}_{25-75 \%}$ (Fig. 3). On average, for every $10 \%$ increase in FOXP3 promoter 2 methylation, there was a $4 \%$ decrease in $\mathrm{FEV}_{1} / \mathrm{FVC}\left(\beta_{\text {estimate }}[95 \% \mathrm{CI}],-0.40[-0.67,-0.13], p<\right.$ $0.01)$. Similarly, for every $10 \%$ increase in FOXP3 promoter 2 methylation, there was a $15 \%$ decrease in $\mathrm{FEF}_{25-75 \%}(-1.46[-2.52,-0.40], p<0.01)$ (Additional file 2: Table S4). Also, in our crude models, there were inverse associations between promoter 1 methylation and both $\mathrm{FEV}_{1} / \mathrm{FVC}(-0.18[-0.30,-0.05], p<0.01)$ and $\mathrm{FEF}_{25-75 \%}$ $(-0.04[-0.07,-0.00], p=0.03)$; however, these findings were not statistically significant after controlling for confounders. There was no significant association between promoter 3 methylation and lung function nor between methylation and $\mathrm{FVC}$ or $\mathrm{FEV}_{1}$. Also, the relationship between promoter 2 methylation and lung function did not significantly vary by high vs. low BC exposure (Additional file 2: Table S5).

\section{Secondary analyses}

First, we performed substitution analysis with FOXP3 relative expression. However, we did not observe a correlation between FOXP3 methylation of any of the three promoter sites with relative mRNA expression (promoter 1: $r=-0.03, p=0.74$; promoter 2: $r=-0.10, p=$ 0.24 ; promoter $3: r=0.05, p=0.57$ ). Nonetheless, in the

Table 2 Active children with high exposure to BC have lower FOXP3 promoter methylation compared to non-active children with high $B C$

\begin{tabular}{|c|c|c|c|c|}
\hline & \multicolumn{4}{|c|}{$\begin{array}{l}\text { Difference in percent methylation in active vs. non-active children } \\
\beta_{\text {estimate }}(95 \% \text { confidence interval) }\end{array}$} \\
\hline & $\begin{array}{l}\text { Overall sample } \\
(n=135)\end{array}$ & $\begin{array}{l}\text { High } B C^{a} \\
(n=63)\end{array}$ & $\begin{array}{l}\text { Low BC } \\
(n=72)\end{array}$ & $p_{\text {interaction }}$ \\
\hline Promoter 1 & $-0.59(-1.72,0.54)$ & $-1.32(-2.74,0.11)$ & $0.30(-1.36,1.97)$ & NA \\
\hline Promoter 2 & $-0.60(-1.79,0.60)$ & $-2.37(-4.04,-0.70)$ & $0.54(-1.12,2.20)$ & 0.04 \\
\hline Promoter 3 & $-0.68(-2.10,0.74)$ & $-2.57(-4.62,-0.51)$ & $-0.41(-2.16,1.34)$ & 0.26 \\
\hline
\end{tabular}

$\beta_{\text {estimate }}$ represents the effect size or the difference in percent methylation when comparing active children to non-active children (reference). Models adjusted for age, sex, race/ethnicity, BMI Z-score, asthma, atopy, secondhand smoke exposure, BC (only in non-stratified model), and heating season. Italicized values represent

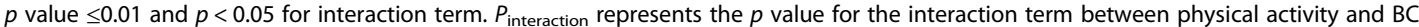

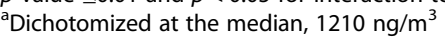




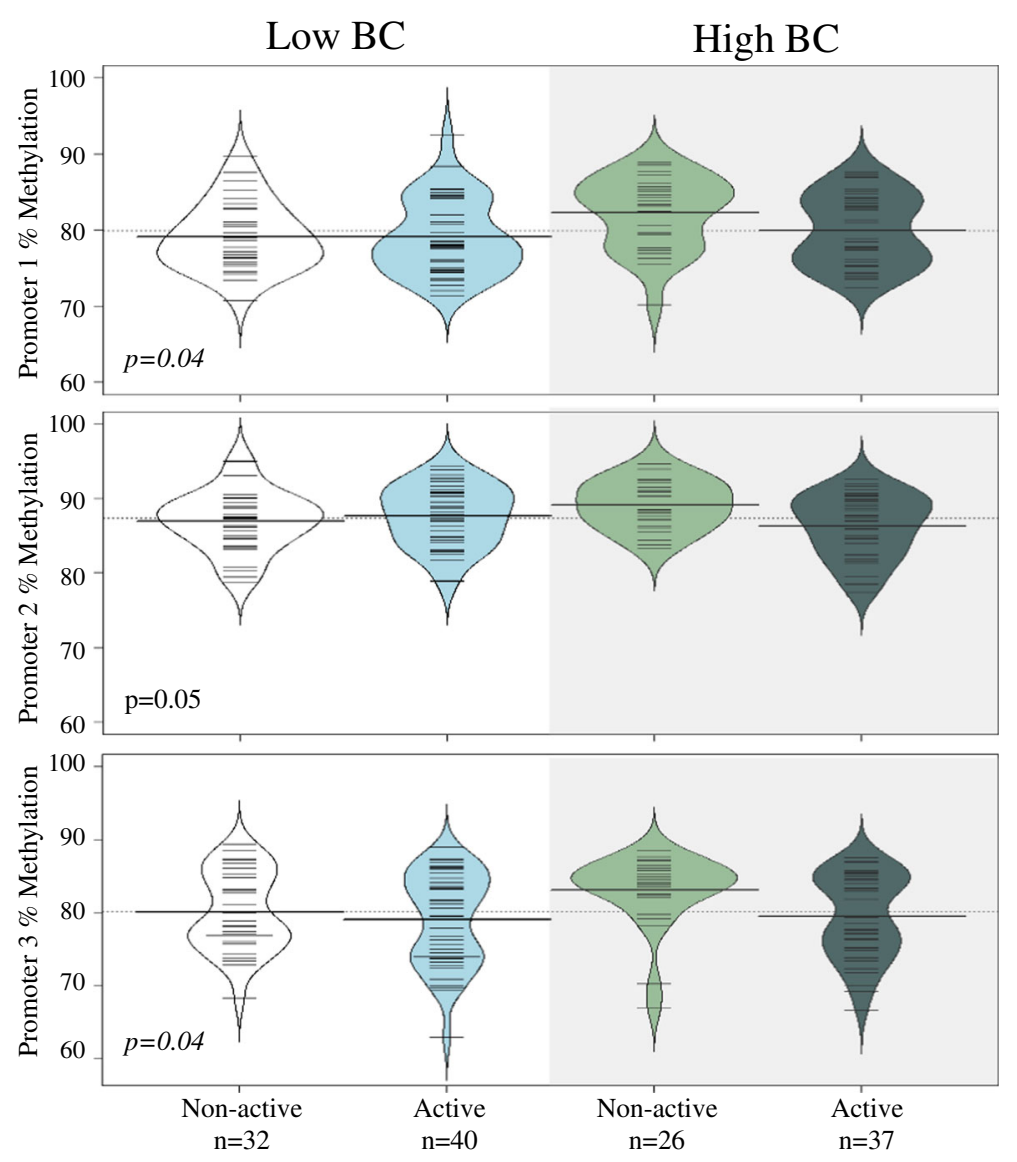

Fig. 2 Non-active children with high BC on average have the highest FOXP3 promoter methylation (Kruskal-Wallis test). The short lines indicate individual observations, while the shaded areas indicated the distribution of the data for each respective group. The dotted lines indicate the mean percent methylation for all participants, and the thicker solid lines represent mean percent methylation for each respective group

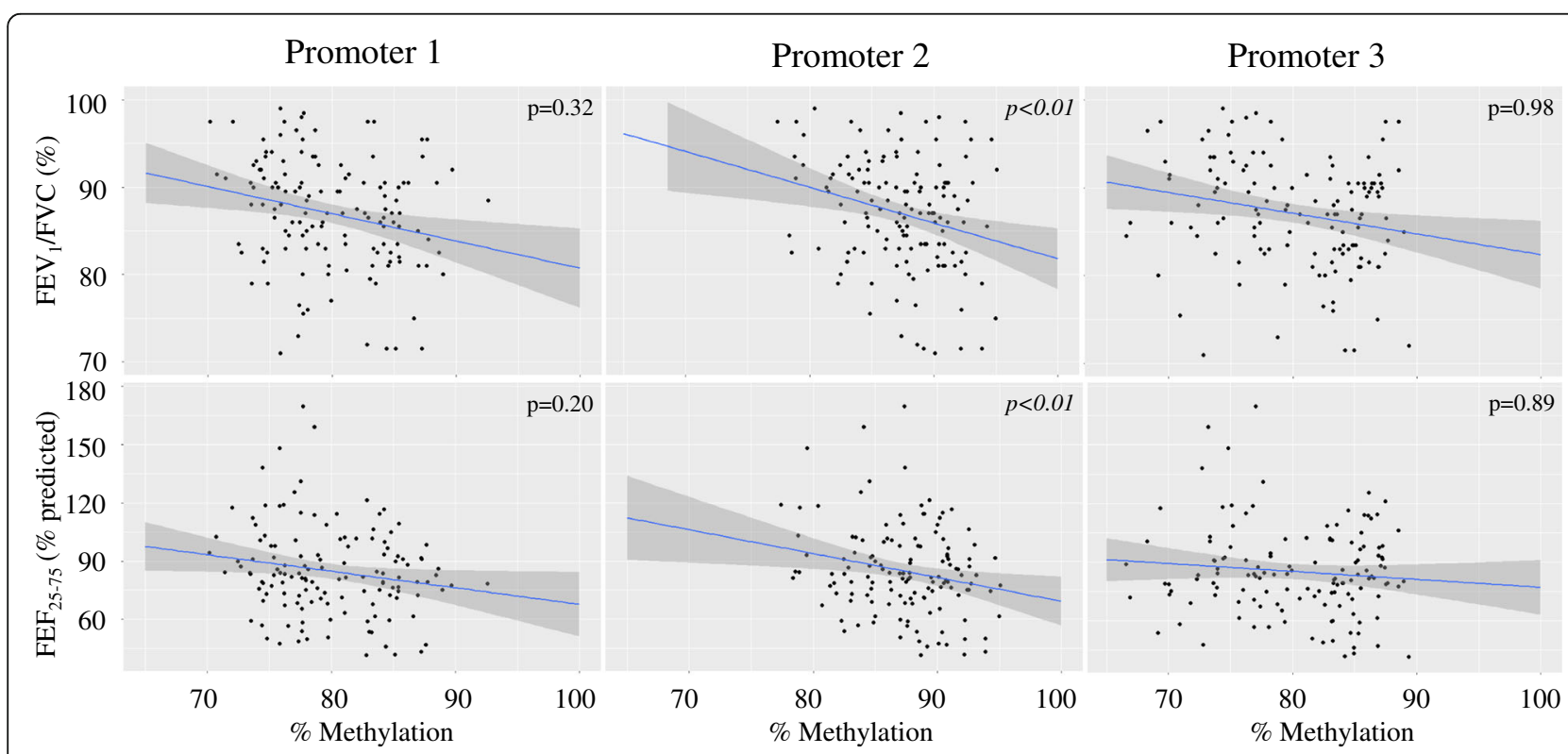

Fig. 3 Lower FOXP3 promoter methylation is associated with higher FEV $1 / F V C$ and $\mathrm{FEF}_{25}-75 \%$. The blue line represents the mean effect estimate, and the shaded gray area represents the 95\% confidence interval $(n=135)$ 
secondary analyses, we substituted FOXP3-relative mRNA expression in our models to explore the relationship with combined activity and $\mathrm{BC}$ concentrations as well as lung function. There was no significant association between physical activity and mRNA expression in the high $\left(\beta_{\text {esti- }}\right.$ mate $[95 \% \mathrm{CI}], 0.02[-0.00,0.05], p=0.11)$ or low $(-0.00$ $[-0.01,0.00], p=0.12)$ personal $\mathrm{BC}$ groups. There was no significant association between relative mRNA expression and lung function (data not shown).

Second, we explored the overall relationship between physical activity and lung function using multivariable linear regression models. We observed a significant positive association between physical activity and $\mathrm{FEF}_{25-75 \%}$. On average, active children had $8 \%$ greater $\mathrm{FEF}_{25-75 \%}$ compared to non-active children (8.07 [0.40, 15.74], $p=0.04)$ (Table 3). To explore relationships among the children with the most extreme pollutant measures and highest risk based on previous findings [6], we further stratified our model by the upper tertile of $\mathrm{BC}$ concentration. Interestingly, among children with the highest $\mathrm{BC}$ exposure, active children had lower $\mathrm{FEV}_{1}$ and $\mathrm{FVC}$ compared to non-active children. Conversely, among children with lower BC exposure, active children had higher $\mathrm{FEV}_{1}$ and $\mathrm{FEF}_{25-75 \%}$ compared to non-active children (Table 3). However, there was no significant interaction between activity and $\mathrm{BC}$ exposure on any of the lung function outcomes (Table 3). Lastly, in ancillary analyses stratified by sex, we observed that FOXP3 promoter methylation was lower in females compared to males $(p<0.01$, Additional file 1: Figures S4 and S5), and the relationships between activity, FOXP3 promoter methylation, and lung function were stronger among females compared to those among males (Additional file 2: Table S6, Additional file 2: Table S7).

\section{Discussion}

In our cohort of 9-14-year-old children of African American and Dominican descent living in NYC, we identified a link between higher combined personal $\mathrm{BC}$ exposure and physical activity and lower FOXP3 promoter methylation. In addition, FOXP3 promoter methylation was inversely associated with $\mathrm{FEV}_{1} / \mathrm{FVC}$ and $\mathrm{FEF}_{25-75 \%}$, the two indicators of airway obstructive physiology [46, 47]. These findings suggest that higher exposure to air pollution may be a condition by which urban children are more likely to gain immunological benefits of regular exercise, and that FOXP3 promoter methylation may function as a biomarker of that benefit.

Our a priori hypothesis was that active children would have lower FOXP3 buccal cell methylation compared to non-active children. Our findings were consistent with this hypothesis only within the promoter 3 region, which is the CpG site most proximal to the transcription start site. An additional hypothesis was that high $\mathrm{BC}$ exposure, which has been associated with adverse respiratory outcomes [25-27], would attenuate the association between physical activity and methylation. Contrary to our hypothesis, the association between physical activity and FOXP3 methylation was only notable among children with high $\mathrm{BC}$ exposure. This may instead suggest that, although physical activity may increase lung deposition of ambient pollutants and thereby increase airway inflammation, a high degree of regular physical activity may induce sufficient protective immune balance to mitigate this effect. FOXP3 promoter methylation levels among active children with high $\mathrm{BC}$ were comparable to both groups of children with low $\mathrm{BC}$ (active and nonactive) (Fig. 2). Thus, we speculate that children with higher risk of Treg impairment due to high exposure to pollutants are the ones able to achieve greater immunologic benefit from regular physical activity. Fisher and colleges recently investigated the interaction between physical activity and nitrogen dioxide $\left(\mathrm{NO}_{2}\right)$ pollutant exposure on respiratory-related hospitalization in a cohort of Danish adults [48]. The authors reported no significant interaction between physical activity and pollutant exposure on hospitalizations for asthma suggesting that the benefits of activity outweighed the risk of pollutant exposure. Through our ability to assess recent activity and acute air pollution with high granularity, our findings further suggest a significant short-term

Table 3 Among children with the upper tertile of exposure to BC, physical activity is associated with reduced lung function, whereas children with less BC exposure experience opposite effects

\begin{tabular}{|c|c|c|c|c|}
\hline & \multicolumn{4}{|c|}{$\begin{array}{l}\text { Difference in methylation in active vs. non-active children } \\
\beta_{\text {estimate }}(95 \% \text { confidence interval) }\end{array}$} \\
\hline & Overall sample $(n=135)$ & $\begin{array}{l}\text { Upper tertile } B C^{a} \\
(n=33)\end{array}$ & $\begin{array}{l}\text { Lower } 2 / 3 \mathrm{BC}^{\mathrm{a}} \\
(n=102)\end{array}$ & $p_{\text {interaction }}$ \\
\hline $\mathrm{FEV}_{1}$ & $2.72(-1.14,6.59)$ & $-7.87(-15.33,-0.42)$ & $4.60(0.21,8.99)$ & 0.09 \\
\hline FVC & $1.25(-2.25,4.75)$ & $-6.91(-13.70,-0.13)$ & $2.70(-1.30,6.70)$ & 0.31 \\
\hline $\mathrm{FEV}_{1} / \mathrm{FVC}$ & $1.36(-0.62,3.33)$ & $-1.09(-5.03,2.5)$ & $1.90(-0.49,4.28)$ & NA \\
\hline $\mathrm{FEF}_{25-75 \%}$ & $8.07(0.40,15.74)$ & $-6.59(-23.0,9.80)$ & $9.60(0.60,18.60)$ & 0.27 \\
\hline
\end{tabular}

$\beta_{\text {estimate }}$ represents the effect size or the difference in percent methylation when comparing active children to non-active children (reference). Models adjusted for age, sex, race/ethnicity, BMI Z-score, asthma, atopy, secondhand smoke exposure, heating season, and BC concentration (only for overall sample model). Italicized values represent $p$ value $\leq 0.05$. $P_{\text {interaction }}$ represents the $p$ value for the interaction term between physical activity and BC

${ }^{a}$ Dichotomized at the upper tertile, $1790 \mathrm{ng} / \mathrm{m}^{3}$ 
positive interaction between pollutant exposure and activity on immune function, as indicated by FOXP3 promoter methylation.

Divergent from previous reports in humans [23], we were unable to detect a correlation between buccal FOXP3 promoter methylation and relative mRNA expression. One possible explanation is that the above mentioned relationship previously has been identified in isolated Treg cells while we sampled buccal cells. Also, currently, there is no standardized method for quantifying methylation across CpG sites within a gene region, thus limiting the ability to compare percent methylation levels across various studies $[13,23]$. To our knowledge, this is one of the first studies to investigate FOXP3 methylation in buccal epithelium; however, our absolute percent methylation levels are comparable to those measured in gingival epithelial cells [49]. Methylation patterns can differ by cell type $[37,50]$, which is likely reflective of lower mRNA expression of immunomodulatory genes in buccal epithelium vs. higher expression among lymphocytes. We previously reported higher methylation in buccal cells compared to CD4+ lymphocytes within the interferon gamma (IFN $\gamma$ ) immunomodulatory gene promoter. Additionally, a significant correlation in IFN $\gamma$ methylation across the cell types was notable for one of the CpG sites [37], suggesting a link between buccal cell and lymphocyte methylation in that particular gene. Buccal cells are easily accessible, apt for repeat testing with changing environmental exposures and less invasive than sampling the blood or lower airway epithelial cells. Thus, they may represent a suitable source of a biomarker for pediatric cohort research.

Notably, our most significant findings were observed in the promoter 2 region that encompasses two of three CpG sites (-77 and -65$)$ that are conserved in humans, mice, and rats [22]. Others also have reported that individual $\mathrm{CpG}$ sites within a gene region may be critical drivers of downstream effects [51, 52]. Our methylation signal was small, and our observed differences in FOXP3 promoter methylation between active and non-active children was about $2.5 \%$ [51,52]. Breton and colleagues also described small differences in buccal cell methylation of several genes between children that were exposed vs. those not exposed to secondhand smoke [53]. Nonetheless, the observation that buccal cells were not completely methylated may suggest that we are capturing a small signal that could reflect larger differences among immune-specific cells. In addition, our observations between methylation and lung function suggest that small changes in buccal epithelial methylation alone could be clinically meaningful. This is consistent with a recent review article that appraised the clinical significance of small-magnitude effect sizes in pediatric environmental epigenetic research, similar to those reported in this current study [54].
Further, the FOXP3 gene is located on the Xchromosome and thus, may be susceptible to $\mathrm{X}$ chromosome inactivation (XCI) in females. This too may be driven and maintained by DNA methylation [44]. However, sex differences in methylation attributed to XCI can vary by location within a gene [55]. In our cohort, we observed lower FOXP3 promoter methylation in females compared to males (Additional file 1: Figures S4 and S5), consistent with the findings in a different cohort of children. In that cohort, differences were more striking and in the opposite direction within the FOXP3 enhancer region [43]. In this current study, the association between physical activity and FOXP3 methylation among children with high $\mathrm{BC}$ was most notable in females compared to males (Additional file 1: Figures S6 and S7, Additional file 2: Table S6). Likewise, the relationship between FOXP3 promoter methylation and lung function was stronger in the females (Additional file 2: Table S7). Overall, these findings underscore the importance of considering sex effects in methylation studies, particularly within genes that are susceptible to XCI.

Breton and colleagues also identified a significant inverse relationship between buccal cell DNA methylation of another asthma gene, arginase (ARG)2, and airway inflammation measured by fractional exhaled nitric oxide (FeNO) [56]. Similarly, Baccarelli and colleagues identified an association between nasal epithelial cell methylation of inducible nitric oxide synthase (iNOS) and interleukin (IL)6 with FeNO, but not with lung function $\left(\mathrm{FEV}_{1}\right)$ [57]. While we too did not appreciate a significant association in methylation of our candidate genes, FOXP3 and $\mathrm{FEV}_{1}$; we did, however, observe associations with $\mathrm{FEV}_{1} / \mathrm{FVC}$ and $\mathrm{FEF}_{25-75 \%}$. Both $\mathrm{FEV}_{1} / \mathrm{FVC}$ [46] and $\mathrm{FEF}_{25-75 \%}$ [47] have been demonstrated as better predictors of airway obstruction [47] and asthma severity [46] compared to $\mathrm{FEV}_{1}$. Furthermore, we observed that active children had higher $\mathrm{FEF}_{25-75 \%}$ compared to non-active children which supports our previous finding of a protective effect of physical activity on airway inflammation [6].

While we believe that our findings are fairly robust, several limitations of our study need to be acknowledged. First, our cross-sectional study design limits our ability to infer causality because of concerns regarding temporality. However, it is unlikely that one's DNA methylation could cause a person to be more or less active or have greater or lesser exposure to air pollution. Also, in the current analysis DNA methylation was averaged across two measurements 5 days apart. This approach was taken to account for variation in methylation that can occur across short time intervals [36]. Also, while we compared FOXP3 promoter methylation to FOXP3 expression among buccal cells, we did not correlate buccal cell FOXP3 methylation with Treg function directly. We acknowledge that our FOXP3 buccal 
cell methylation is not equivalent for measuring altered Treg function related to physical activity, lung function, and exposure to pollutants in immune tissues. Rather, our findings suggest that FOXP3 promoter methylation should be further explored as a biomarker of activity-mediated immune regulation. Generalizability of our findings is limited given our selected population of African American and Dominican children that live in an urban environment. However, one rationale for this selective cohort is that minority children in urban populations that we sampled here are at the greatest risk for asthma-associated morbidity $[58,59]$. Similarly, the exploratory observations between physical activity and lung function that differed by high and low $\mathrm{BC}$ concentrations may be even more robust in a larger sample of children. However, the parent study was not designed or adequately powered to assess these relationships.

\section{Conclusions}

We have demonstrated that combined physical activity and personal $\mathrm{BC}$ exposure may influence FOXP3 promoter DNA methylation and that FOXP3 promoter methylation is related to lung function. Our study has identified a unique subgroup of children with high $\mathrm{BC}$ exposure that may benefit the most from regular physical activity. While the mechanisms are unknown, these findings suggest that exercise may be associated with a protective immune response in the setting of high pollution exposure. FOXP3 promoter methylation may be a useful biomarker of this protection. Overall, our findings are supportive of both the use of buccal cells for DNA methylation studies as well as a possible role of DNA methylation in respiratory outcomes.

\section{Additional files}

Additional file 1: Figure S1. Sampling scheme for accelerometer, black carbon (BC), buccal swabs for DNA and RNA analysis and spirometry. Figure S2. Schematic representation of the FOXP3 gene and the six CpG sites in the promoter region that were investigated. TSS transcription start site, TSDR Treg-specific demethylated region, CNS conserved non-coding sequence. Figure S3. Correlations of FOXP3 methylation across promoter regions and with mRNA relative expression. Figure S4. Distribution of FOXP3 promoter methylation in females vs. males stratified by physical activity (active vs. non-active). Females have lower FOXP3 promoter methylation compared to males. Figure S5. Distribution of FOXP3 promoter methylation in females vs. males stratified by BC concentration (low vs. high). Females have lower FOXP3 promoter methylation compared to males. Figure S6. Distribution of FOXP3 promoter methylation stratified by combined activity and BC concentration in females $(n=67)$. Figure S7. Distribution of FOXP3 promoter methylation stratified by combined activity and BC concentration in males $(n=68)$.

Additional file 2: Table S1. Primers for PCR and pyrosequencing experiments. Table S2. Correlations of day 1 vs. day 6 FOXP3 methylation and mRNA expression. Table S3. Among children with high BC exposure, there is a trend towards active children (coded 1) having a greater odds of lower methylation compared to non-active children (coded 0). Table S4. Higher FOXP3 promoter 2 methylation is associated with overall lower lung function $(n=135)$. Table S5. The relationship between FOXP3 promoter 2 methylation and lung function does not significantly vary by high vs. low BC exposure. Table S6. Among children with high BC, the association between physical activity and FOXP3 promoter methylation is greater in females. Table S7. The relationship between FOXP3 promoter methylation and lung function is greater among females compared to that among males.

\section{Abbreviations}

ARG: Arginase; BC: Black carbon; BMI: Body mass index; CCCEH: Columbia Center for Children's Environmental Health; CSTA: Cystatin A; FEF $25-$ 75\%: Forced expiratory flow at 25-75\%; FeNO: Fractional exhaled nitric oxide; $\mathrm{FEV}_{1}$ : Forced expiratory value in $1 \mathrm{~s}$; FOXP3: Forkhead box p3; FVC: Forced vital capacity; IFNY: Interferon gamma; IgE: Immunoglobulin E; IL6: Interleukin 6; iNOS: Inducible nitric oxide synthase; MVA: Moderate-to-vigorous activity; $\mathrm{NO}_{2}$ : Nitrogen dioxide; NYC: New York City; PAH: Polycyclic aromatic hydrocarbon; PCR: Polymerase chain reaction; PM: Particulate matter; SHS: Second hand smoke; Treg: Regulatory T cell; TSDR: Treg-cell-specific demethylated region; $\mathrm{XCl}$ : X-chromosome inactivation

\section{Acknowledgements}

The authors would like to acknowledge Dr. Roger Vaughan for his guidance and contributions to the statistical analysis for this manuscript.

\section{Funding}

The funding sources of this study were from the NIH (4R01ES013163-10, 3R01ES013163-07S1, KL2 TR00008, P01ES09600, P50ES015905 R01ES08977, P30ES09089, and S100D016219-01), EPA (R827027, RD832141, and RD834509), Columbia University Provost's Grants Program for Junior Faculty, The Educational Foundation of America, The John \& Wendy Neu Family Foundation, the New York Community Trust, and The Trustees of the Blanchette Hooker Rockefeller Fund.

\section{Availability of data and materials}

The datasets used and/or analyzed during the current study are available from the corresponding author on reasonable request.

\section{Authors' contributions}

SLD developed the concept of this particular study, supervised the data collection, performed all the data analysis, drafted the initial manuscript, and approved the final manuscript as submitted. $\mathrm{KHJ}$ supervised the data collection, advised on the analysis of the data, was a major contributor in writing the manuscript and the approval of the final manuscript as submitted. JRJ performed all the DNA methylation experiments, critically reviewed and revised the manuscript, and approved of the final manuscript as submitted. DZT performed all RNA experiments, was a major contributor in writing the manuscript and the approval of the final manuscript as submitted. MDS developed the assays for FOXP3 analysis, critically reviewed and revised the manuscript, and approved the final manuscript as submitted. BY helped design and advise the black carbon data collection, reviewed the manuscript, and approved the final manuscript as submitted. FPP established the longitudinal birth cohort, critically reviewed the manuscript, and approved the final manuscript as submitted. AGR advised on the analysis of the data, critically reviewed the manuscript, and approved the final manuscript as submitted. SNC designed and advised the black carbon data collection, critically reviewed the manuscript, and approved the final manuscript as submitted. MSP was a major contributor in writing the manuscript and approved the final manuscript as submitted. RLM assisted with the original concept of this particular study, supervised all data collection, was a major contributor in writing the manuscript, and approved the final manuscript as submitted. All authors read and approved the final manuscript.

\section{Competing interests}

The authors declare that they have no competing interests

\section{Consent for publication}

Not applicable.

Ethics approval and consent to participate

This study was conducted in accordance with the Columbia University Institutional Review Board guidelines, and informed consents and assents were obtained for all the subjects. 


\section{Publisher's Note}

Springer Nature remains neutral with regard to jurisdictional claims in published maps and institutional affiliations.

\section{Author details}

'Division of Pediatric Pulmonology, Department of Pediatrics, College of Physicians and Surgeons, Columbia University, 3959 Broadway CHC-745, New York, NY 10032, USA. ${ }^{2}$ Division of Pulmonary, Allergy and Critical Care of Medicine, Department of Medicine, College of Physicians and Surgeons, Columbia University, PH8E-101, 630 W. 168 St, New York, NY 10032, USA. ${ }^{3}$ Department of Neurology, Columbia University Medical Center, 710 W. 168th St, New York, NY 10032, USA. " Lamont-Doherty Earth Observatory, Columbia University, 61 Rt, 9 W Palisades, New York 10964, NY, USA. ${ }^{5}$ Department of Environmental Health Sciences and Columbia Center for Children's Environmental Health, Mailman School of Public Health, Columbia University, 722 W. 168 St, New York, NY 10032, USA. 'Department of Epidemiology, Mailman School of Public Health, Columbia University, 722 W. 168 St, New York, NY 10032, USA. ”Division of Pediatric Allergy, Immunology, and Rheumatology, Department of Pediatrics, College of Physicians and Surgeons, Columbia University, PH8E-101, 630 W. 168 St, New York, NY 10032, USA.

Received: 28 December 2016 Accepted: 2 June 2017

Published online: 13 June 2017

\section{References}

1. Eichenberger PA, Diener SN, Kofmehl R, Spengler CM. Effects of exercise training on airway hyperreactivity in asthma: a systematic review and metaanalysis. Sports Med. 2013;43(11):1157-70

2. McConnell R, Berhane K, Yao L, et al. Traffic, susceptibility, and childhood asthma. Environ Health Perspect. 2006;114(5):766-72.

3. Spira-Cohen A, Chen LC, Kendall M, Lall R, Thurston GD. Personal exposures to traffic-related air pollution and acute respiratory health among Bronx schoolchildren with asthma. Environ Health Perspect. 2011;119(4):559-65.

4. Rundell KW, Slee JB, Caviston R, Hollenbach AM. Decreased lung function after inhalation of ultrafine and fine particulate matter during exercise is related to decreased total nitrate in exhaled breath condensate. Inhal Toxicol. 2008;20(1):1-9

5. McCreanor J, Cullinan P, Nieuwenhuijsen MJ, et al. Respiratory effects of exposure to diesel traffic in persons with asthma. N Engl J Med. 2007; 357(23):2348-58.

6. Lovinsky-Desir S, Jung KH, Rundle AG, et al. Physical activity, black carbon exposure and airway inflammation in an urban adolescent cohort. Environ Res. 2016:151:756-62.

7. McConnell R, Berhane $K$, Gilliland $F$, et al. Asthma in exercising children exposed to ozone: a cohort study. Lancet. 2002;359(9304):386-91.

8. Oravisjarvi K, Pietikainen M, Ruuskanen J, Rautio A, Voutilainen A, Keiski RL. Effects of physical activity on the deposition of traffic-related particles into the human lungs in silico. Sci Total Environ. 2011;409(21):4511-8.

9. Cutrufello PT, Smoliga JM, Rundell KW. Small things make a big difference: particulate matter and exercise. Sports Med. 2012;42(12):1041-58.

10. Pedersen BK, Hoffman-Goetz L. Exercise and the immune system: regulation, integration, and adaptation. Physiol Rev. 2000;80(3):1055-81.

11. Lowder T, Dugger K, Deshane J, Estell K, Schwiebert LM. Repeated bouts of aerobic exercise enhance regulatory $T$ cell responses in a murine asthma model. Brain Behav Immun. 2010;24(1):153-9.

12. Yeh $\mathrm{SH}$, Lai HL, Hsiao CY, et al. Moderate physical activity of music aerobic exercise increases lymphocyte counts, specific subsets, and differentiation. J Phys Act Health. 2014;11(7):1386-92.

13. Nadeau K, McDonald-Hyman C, Noth EM, et al. Ambient air pollution impairs regulatory T-cell function in asthma. J Allergy Clin Immunol. 2010; 126(4):845-52. e810.

14. Hew KM, Walker Al, Kohli A, et al. Childhood exposure to ambient polycyclic aromatic hydrocarbons is linked to epigenetic modifications and impaired systemic immunity in T cells. Clin Exp Allergy. 2015;45(1):238-48.

15. Kearley J, Barker JE, Robinson DS, Lloyd CM. Resolution of airway inflammation and hyperreactivity after in vivo transfer of CD4+CD25+ regulatory $T$ cells is interleukin 10 dependent. J Exp Med. 2005;202(11):1539-47.

16. Lewkowich IP, Herman NS, Schleifer KW, et al. CD4+CD25+ T cells protect against experimentally induced asthma and alter pulmonary dendritic cell phenotype and function. J Exp Med. 2005;202(11):1549-61.
17. Nguyen KD, Vanichsarn C, Fohner A, Nadeau KC. Selective deregulation in chemokine signaling pathways of CD4+CD25(hi)CD127(lo)/(-) regulatory $T$ cells in human allergic asthma. J Allergy Clin Immunol. 2009;123(4):933-9. e910.

18. Hori S, Nomura T, Sakaguchi S. Control of regulatory T cell development by the transcription factor Foxp3. Science. 2003;299(5609):1057-61.

19. Baron U, Floess S, Wieczorek $G$, et al. DNA demethylation in the human FOXP3 locus discriminates regulatory T cells from activated FOXP3(+) conventional T cells. Eur J Immunol. 2007;37(9):2378-89.

20. Floess S, Freyer J, Siewert C, et al. Epigenetic control of the foxp3 locus in regulatory T cells. PLoS Biol. 2007;5(2):e38.

21. Polansky JK, Kretschmer K, Freyer J, et al. DNA methylation controls Foxp3 gene expression. Eur J Immunol. 2008;38(6):1654-63.

22. Janson PC, Winerdal ME, Marits $P$, Thorn M, Ohlsson R, Winqvist O. FOXP3 promoter demethylation reveals the committed Treg population in humans. PLoS One. 2008:3(2):e1612.

23. Kohli A, Garcia MA, Miller RL, et al. Secondhand smoke in combination with ambient air pollution exposure is associated with increasedx CpG methylation and decreased expression of IFN-gamma in T effector cells and Foxp3 in T regulatory cells in children. Clin Epigenetics. 2012;4(1):17.

24. Brunst KJ, Leung YK, Ryan PH, et al. Forkhead box protein 3 (FOXP3) hypermethylation is associated with diesel exhaust exposure and risk for childhood asthma. J Allergy Clin Immunol. 2013;131(2):592-4. e591-593.

25. Jung KH, Hsu SI, Yan B, et al. Childhood exposure to fine particulate matter and black carbon and the development of new wheeze between ages 5 and 7 in an urban prospective cohort. Environ Int. 2012;45:44-50.

26. Cornell AG, Chillrud SN, Mellins RB, et al. Domestic airborne black carbon and exhaled nitric oxide in children in NYC. J Expo Sci Environ Epidemiol. 2012;22(3):258-66.

27. Lepeule J, Bind MA, Baccarelli AA, et al. Epigenetic influences on associations between air pollutants and lung function in elderly men: the normative aging study. Environ Health Perspect. 2014;122(6):566-72.

28. Allam JP, Duan Y, Winter J, et al. Tolerogenic T cells, Th1/Th17 cytokines and TLR2/TLR4 expressing dendritic cells predominate the microenvironment within distinct oral mucosal sites. Allergy. 2011;66(4):532-9.

29. Miller RL, Garfinkel R, Horton M, et al. Polycyclic aromatic hydrocarbons, environmental tobacco smoke, and respiratory symptoms in an inner-city birth cohort. Chest. 2004;126:1071-8.

30. Perera FP, Rauh $V$, Tsai $W-Y$, et al. Effects of transplacental exposure to environmental pollutants on birth outcomes in a multiethnic population. Environ Health Perspect. 2003;111(2):201-5.

31. Donohue KM, Miller RL, Perzanowski MS, et al. Prenatal and postnatal bisphenol A exposure and asthma development among inner-city children. J Allergy Clin Immunol. 2013;131(3):736-42.

32. Rundle A, Goldstein IF, Mellins RB, Ashby-Thompson M, Hoepner L, Jacobson JS. Physical activity and asthma symptoms among New York City Head Start children. J Asthma. 2009;46(8):803-9.

33. Lovinsky-Desir S, Folch C, Jung KH, et al. Urban adolescents readily comply with a complicated asthma research protocol. Clin Med Insights Circ Respir Pulm Med. 2014:8:5-9.

34. Cai J, Yan B, Kinney PL, et al. Optimization approaches to ameliorate humidity and vibration related issues using the microAeth black carbon monitor for personal exposure measurement. Aerosol Sci Technol. 2013;47(11):1196-204.

35. Cai J, Yan B, Ross J, et al. Validation of microAeth(R) as a black carbon monitor for fixed-site measurement and optimization for personal exposure characterization. Aerosol Air Qual Res. 2014;14(1):1-9.

36. Torrone D, Kuriakose J, Moors K, et al. Reproducibility and intraindividual variation over days in buccal cell DNA methylation of two asthma genes, interferon gamma (IFNgamma) and inducible nitric oxide synthase (iNOS). Clin Epigenetics. 2012;4(1):3.

37. Lovinsky-Desir S, Ridder R, Torrone $D$, et al. DNA methylation of the allergy regulatory gene interferon gamma varies by age, sex, and tissue type in asthmatics. Clin Epigenetics. 2014;6(1):9.

38. Jung KH, Torrone DZ, Lovinsky-Desir S, Perzanowski M, Bautista J, Jezioro J, Hoepner L, Ross J, Perera F, Chillrud SN, Miller R. Short-term exposure to PM2.5 and vanadium and changes in asthma gene DNA methylation and lung function decrements among urban children. Respir Res. 2017;18(1):63.

39. Huehn J, Polansky JK, Hamann A. Epigenetic control of FOXP3 expression: the key to a stable regulatory T-cell lineage? Nat Rev Immunol. 2009;9(2):83-9.

40. Schreiber L, Pietzsch B, Floess S, et al. The Treg-specific demethylated region stabilizes Foxp3 expression independently of NF-kappaB signaling. PLoS One. 2014;9(2):e88318. 
41. Magister S, Kos J. Cystatins in immune system. J Cancer. 2013;4(1):45-56.

42. Loeb JS, Blower WC, Feldstein JF, Koch BA, Munlin AL, Hardie WD. Acceptability and repeatability of spirometry in children using updated ATS/ ERS criteria. Pediatr Pulmonol. 2008:43(10):1020-4.

43. Miller RL, Zhang H, Jezioro J, et al. Reduced mouse allergen is associated with epigenetic changes in regulatory genes, but not mouse sensitization, in asthmatic children. Environ Res. 2017;156:619-24.

44. Carrel L, Willard HF. X-inactivation profile reveals extensive variability in X-linked gene expression in females. Nature. 2005;434(7031):400-4.

45. https://www.cdc.gov/growthcharts/zscore.htm. Accessed 28 Dec, 2016.

46. Bacharier LB, Strunk RC, Mauger D, White D, Lemanske Jr RF, Sorkness CA. Classifying asthma severity in children: mismatch between symptoms, medication use, and lung function. Am J Respir Crit Care Med. 2004;170(4): 426-32

47. Lebecque $\mathrm{P}$, Kiakulanda $\mathrm{P}$, Coates AL. Spirometry in the asthmatic child: is FEF25-75 a more sensitive test than FEV1/FVC? Pediatr Pulmonol. 1993;16(1): 19-22.

48. Fisher JE, Loft S, Ulrik CS, et al. Physical activity, air pollution, and the risk of asthma and chronic obstructive pulmonary disease. Am J Respir Crit Care Med. 2016;194(7):855-65.

49. Campos K, Franscisconi CF, Okehie V, et al. FOXP3 DNA methylation levels as a potential biomarker in the development of periapical lesions. J Endod. 2015;41(2):212-8.

50. Stefanowicz D, Hackett TL, Garmaroudi FS, et al. DNA methylation profiles of airway epithelial cells and PBMCs from healthy, atopic and asthmatic children. PLoS One. 2012;7(9):e44213.

51. Clifford RL, Jones MJ, Maclsaac JL, et al. Inhalation of diesel exhaust and allergen alters human bronchial epithelium DNA methylation. J Allergy Clin Immunol. 2016;139(1):112-21.

52. Jones B, Chen J. Inhibition of IFN-gamma transcription by site-specific methylation during T helper cell development. EMBO J. 2006;25(11):2443-52.

53. Breton CV, Byun HM, Wenten M, Pan F, Yang A, Gilliland FD. Prenatal tobacco smoke exposure affects global and gene-specific DNA methylation. Am J Respir Crit Care Med. 2009;180(5):462-7.

54. Breton CV, Marsit CJ, Faustman E, et al. Small-magnitude effect sizes in epigenetic end points are important in children's environmental health studies: the Children's Environmental Health and Disease Prevention Research Center's Epigenetics Working Group. Environ Health Perspect. 2017:125(4):511-26.

55. Sharp AJ, Stathaki E, Migliavacca E, et al. DNA methylation profiles of human active and inactive X chromosomes. Genome Res. 2011;21(10):1592-600

56. Breton CV, Byun HM, Wang X, Salam MT, Siegmund K, Gilliland FD. DNA methylation in the arginase-nitric oxide synthase pathway is associated with exhaled nitric oxide in children with asthma. Am J Respir Crit Care Med. 2011;184(2):191-7.

57. Baccarelli A, Rusconi F, Bollati V, et al. Nasal cell DNA methylation, inflammation, lung function and wheezing in children with asthma. Epigenomics. 2012;4(1):91-100.

58. Akinbami $\sqcup$, Moorman JE, Liu X. Asthma prevalence, health care use, and mortality: United States, 2005-2009. Natl Health Stat Report. 2011;(32):1-14

59. Togias A, Fenton MJ, Gergen PJ, Rotrosen D, Fauci AS. Asthma in the inner city: the perspective of the National Institute of Allergy and Infectious Diseases. J Allergy Clin Immunol. 2010;125(3):540-4.

\section{Submit your next manuscript to BioMed Central and we will help you at every step:}

- We accept pre-submission inquiries

- Our selector tool helps you to find the most relevant journal

- We provide round the clock customer support

- Convenient online submission

- Thorough peer review

- Inclusion in PubMed and all major indexing services

- Maximum visibility for your research

Submit your manuscript at www.biomedcentral.com/submit
Biomed Central 